12

\title{
Экспериментальная оценка взрыво- и пожароопасности литиевых источников тока
}

\author{
(c) В.А. Архипов, А.И. Коноваленко, В.Т. Кузнецов, А.С. Жуков \\ Национальный исследовательский Томский государственный университет, Томск, Россия \\ E-mail: zharova@niipmm.tsu.ru
}

Поступило в Редакцию 15 октября 2018 г.

В окончательной редакции 26 апреля 2019 г.

Принято к публикации 26 апреля 2019 г.

\begin{abstract}
Предложена методика количественной оценки взрыво- и пожароопасности литий-тионилхлоридных элементов, описана экспериментальная установка и приведены результаты экспериментов с литийтионилхлоридными элементами типоразмеров D и DD.
\end{abstract}

Ключевые слова: химический источник тока, взрыво- и пожароопасность, манометрическая бомба, давление.

DOI: 10.21883/PJTF.2019.15.48082.17561

Литий-тионилхлоридные $\left(\mathrm{Li} / \mathrm{SOCl}_{2}\right)$ химические источники тока обладают высокой плотностью энергии, широким диапазоном эксплуатационных температур, длительным сроком хранения [1]. В настоящее время для электропитания различных объектов широко применяются литий-тионилхлоридные элементы (ТХЛ-элементы) отечественных (НПП „Литий“, Дубна; АО ИФ „Орион-ХИТ“, Новочеркасск; АО „Литий-элемент“, Саратов) и зарубежных („SAFT“, Франция; „ЕVE ENERGY Со.“, Китай; „ЕXIUM““, Южная Корея и др.) производителей.

Основным недостатком ТХЛ-элементов является их повышенная взрыво- и пожароопасность, связанная с возможностью возникновения неуправляемых экзотермических химических реакций при нештатных ситуациях их эксплуатации (перегрев, повреждения корпуса, разгерметизация, перезаряд или переразряд) [2,3]. В ГОСТ Р МЭК 60086-4-2009 [4] описаны методики испытаний на внутреннее короткое замыкание при неправильном применении ТХЛ-элементов. В соответствии с [4] определяется только факт возникновения взрыва или возгорания ТХЛ-элемента. Количественное определение характеристик этих процессов является объективной информацией для потребителей, позволяющей оценивать масштабы негативного воздействия результатов нештатных ситуаций при эксплуатации ТХЛ-элементов на оборудование и обслуживающий персонал.

В настоящей работе рассмотрена методика количественной оценки энергии взрыва и горения ТХЛ-элементов при возникновении внутреннего короткого замыкания вследствие механического повреждения их корпуса.

Для количественной оценки энергии взрыва и горения ТХЛ-элемента предлагается осуществлять его взрыв в манометрической бомбе постоянного объема (МБ), которая широко применяется для исследования горения порохов и взрывчатых веществ [5]. Повреждение корпуса ТХЛ-элемента осуществляется его пробитием заостренным металлическим стержнем поперек оси симметрии элемента. При этом происходит короткое замыкание обкладок элемента и максимальное выделение энергии. По величине изменения давления в МБ при взрыве и горении ТХЛ-элемента рассчитываются тротиловый эквивалент взрыва и количество теплоты, выделяемой при последующем горении содержимого ТХЛ-элемента [6].

Схема МБ для определения характеристик взрыва и горения ТХЛ-элемента приведена на рис. 1. МБ содержит корпус 1 с крышкой 2 , кольцевой гайкой 3 и уплотнителем 4. В корпусе размещается подложка 17 с испытываемым ТХЛ-элементом 16. По оси крышки 2 установлена втулка 5 с осевым отверстием, в котором располагается заостренный стержень 8. Метание стержня 8 осуществляется пороховым зарядом 10, размещенным в полости 18 переходника 6 , инициируемым электрическим капсюлем-воспламенителем 9. Переходник 6 закрыт пробкой 7 с центральным электродом 11 и электрическим изолятором 12. В корпусе МБ имеются гнезда для установки датчика давления 13 и клапана сброса давления 14 с шаровым элементом 15, подсоединенного к вытяжной системе 19.

Для определения энергии взрыва и горения ТХЛэлемента использовалась МБ с внутренним диаметром $120 \mathrm{~mm}$ и свободным объемом $V=21$. Пробивание ТХЛэлемента осуществлялось заостренным металлическим стержнем диаметром $4.5 \mathrm{~mm}$ и длиной $40 \mathrm{~mm}$.

Типичные осциллограммы изменения давления в МБ при пробитии ТХЛ-элемента приведены на рис. 2, $a$ и 3,a. Теплота, выделяемая при взрыве ТХЛ-элемента в МБ при отсутствии тепловых потерь через стенки бомбы, расходуется только на повышение внутренней энергии газа:

$$
Q_{\mathrm{EXP}}=\Delta U=U_{1}-U_{0},
$$

где $Q_{\mathrm{EXP}}$ - количество теплоты, выделяемое при взрыве $[\mathbf{J}], \Delta U-$ изменение внутренней энергии газа $[\mathbf{J}]$, $U_{1}, U_{0}$ - конечное и начальное значения внутренней энергии газа $[\mathbf{J}]$. 


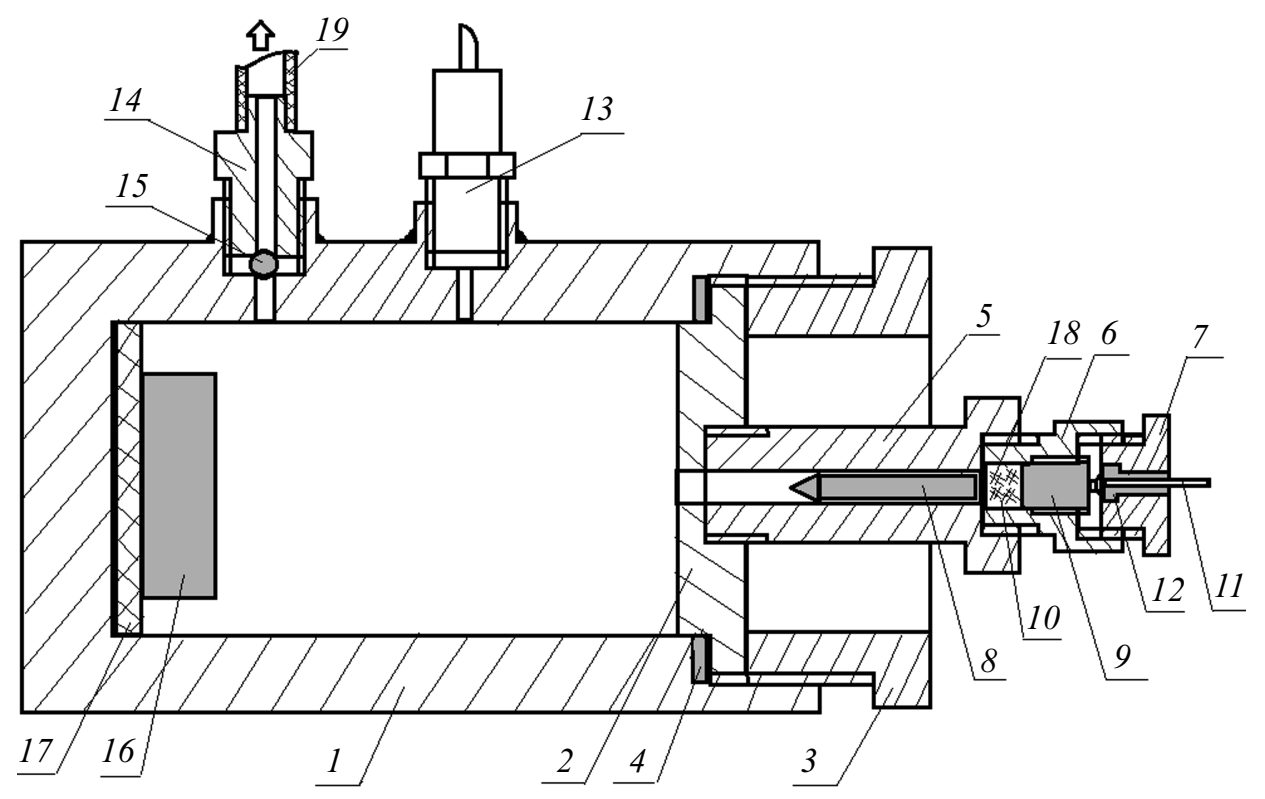

Рис. 1. Схема МБ для определения характеристик взрыва ТХЛ-элемента. Пояснения в тексте.
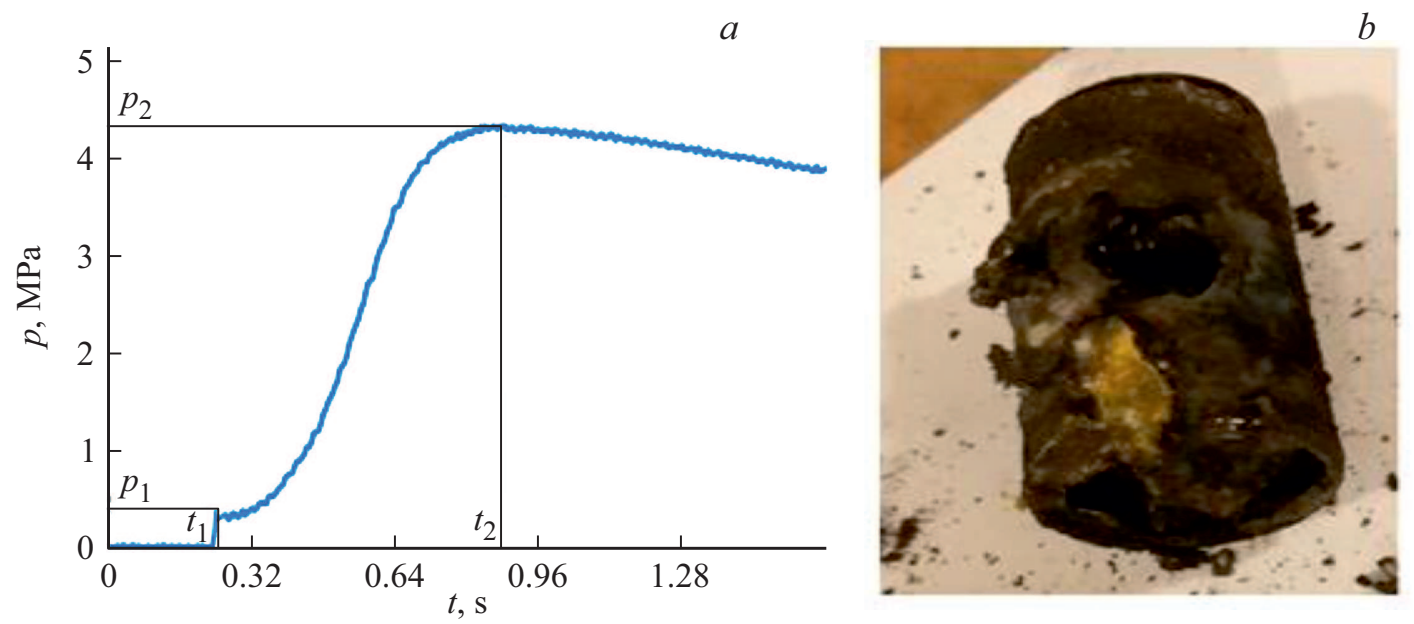

Рис. 2. Изменение давления в МБ при взрыве ТХЛ-элемента типа ER34615M фирмы EVE ENERGY $(a)$ и вид элемента после испытаний $(b)$.

Внутренняя энергия газа определяется формулой [7]:

$$
U=\rho V C_{V} T,
$$

где $\rho$ - плотность газа $\left[\mathrm{kg} / \mathrm{m}^{3}\right], C_{V}-$ удельная изохорическая теплоемкость газа $[\mathrm{J} /(\mathrm{kg} \cdot \mathrm{K})], T$ - температура газа $[\mathrm{K}]$.

Используя уравнение состояния Менделеева-Клапейрона $p=\rho R T$ и уравнение Майера $R=C_{P}-C_{V}$, выражение для внутренней энергии газа (2) можно представить в виде

$$
U=\frac{V}{k-1} p,
$$

где $C_{P}-$ удельная изобарическая теплоемкость газа $[\mathrm{J} /(\mathrm{kg} \cdot \mathrm{K})], R$ и $k=C_{P} / C_{V}$ - газовая постоянная и показатель адиабаты газообразных продуктов взрыва.
Тогда выражение (1) с учетом (3) примет вид

$$
Q_{\mathrm{EXP}}=\frac{V}{k-1}\left(p_{1}-p_{0}\right),
$$

где $p_{0}=0.1 \mathrm{MPa}-$ начальное давление, $p_{1}$ - пиковое значение давления (рис. 2, 3).

Для оценки взрывоопасности ТХЛ-элемента удобно использовать массу тринитротолуола (тротила) $m_{\mathrm{TNT}}$, при взрыве которой выделяется энергия, равная энергии взрыва ТХЛ-элемента $Q_{\mathrm{EXP}}$. Расчет $m_{\mathrm{TNT}}$ проводится по формуле

$$
m_{\mathrm{TNT}}=\frac{Q_{\mathrm{EXP}}}{q_{\mathrm{TNT}}},
$$

где $q_{\mathrm{TNT}}=4.52 \mathrm{MJ} / \mathrm{kg}-$ удельная энергия взрыва тротила [8]. 

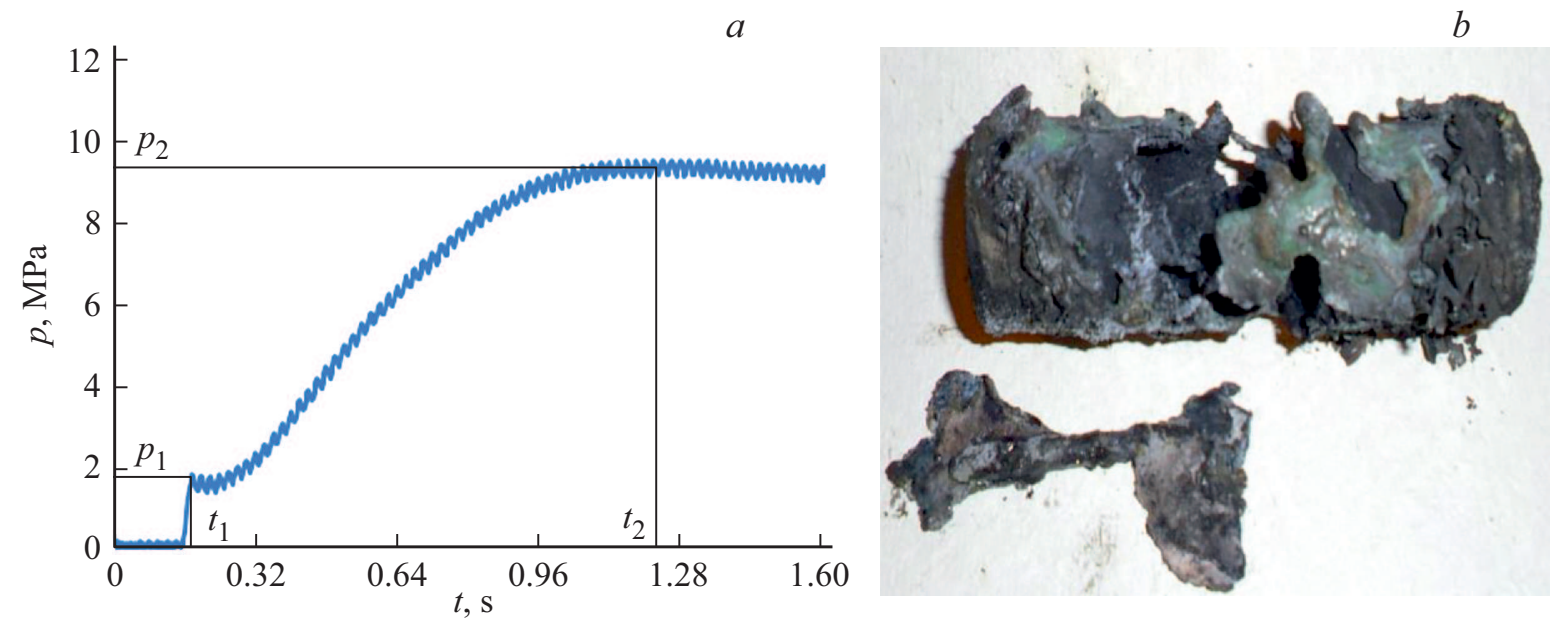

Рис. 3. Изменение давления в МБ при взрыве ТХЛ-элемента 130916-01Н DD фирмы EXIUM (a) и вид элемента после испытаний $(b)$.

Результаты испытаний ТХЛ-элементов различных производителей в МБ

\begin{tabular}{|c|c|c|c|c|c|c|}
\hline \multirow[b]{2}{*}{ Характеристика } & \multicolumn{6}{|c|}{ Производитель } \\
\hline & $\begin{array}{c}\text { EVE ENERGY } \\
\text { (Китай })\end{array}$ & $\begin{array}{c}\text { SAFN } \\
\text { (Франция) }\end{array}$ & $\begin{array}{l}\text { MINAMOTO } \\
\text { (Китай) }\end{array}$ & $\begin{array}{l}\text { FANSO } \\
\text { (Китай) }\end{array}$ & $\begin{array}{c}\text { EXIUM } \\
\text { (Южная Корея) }\end{array}$ & $\begin{array}{c}\text { ELECTROCHEM } \\
\text { (СШA) }\end{array}$ \\
\hline $\begin{array}{c}\text { Марка } \\
\text { Типоразмер } \\
\text { Энергоемкость, Ah } \\
\text { Масса TNT взрыва, g } \\
\text { Тепловыделение при горении } Q, \mathrm{~kJ}\end{array}$ & $\begin{array}{c}\text { ER34615M } \\
\text { D } \\
14 \\
0.5 \\
3.9\end{array}$ & $\begin{array}{c}\text { LSH } 20 \text { hts } \\
\text { D } \\
13 \\
0.55 \\
19.6\end{array}$ & $\begin{array}{c}\text { ER-34615M (D) } \\
\text { D } \\
16.5 \\
0.15 \\
14.6\end{array}$ & $\begin{array}{c}\text { ER34615M } \\
\text { D } \\
14 \\
0.33 \\
4.6\end{array}$ & $\begin{array}{l}\text { SC-DD01 } \\
\text { DD } \\
27-32 \\
2.4 \\
15.6\end{array}$ & $\begin{array}{c}\text { CSC } 93 \text { DD } \\
\text { DD } \\
30 \\
7.2 \\
19.9\end{array}$ \\
\hline
\end{tabular}

При воспламенении и горении ТХЛ-элемента давление в МБ повышается от пикового значения $p_{1}$ (в момент взрыва $t_{1}$ ) (рис. 2, 3) до максимального давления $p_{2}$ (достигаемого в момент времени $t_{2}$ ).

Полагая, что количество теплоты, выделяемое при горении ТХЛ-элемента в МБ при отсутствии тепловых потерь, расходуется только на повышение внутренней энергии газа, по аналогии с тепловыделением при взрыве ТХЛ-элемента получим выражение

$$
Q_{\mathrm{COM}}=\frac{V}{k-1}\left(p_{2}-p_{1}\right) .
$$

Эксперименты показали, что изменение давления в МБ при срабатывании заряда бездымного пороха массой $0.15 \mathrm{~g}$ не превышает $0.01 \mathrm{MPa}$, однако стержень пробивает ТХЛ-элемент насквозь. При испытании ТХЛ-элемента в момент пробития стержнем происходит внутреннее короткое замыкание, которое сопровождается выбросом газообразных продуктов (взрывом) и пиком давления в МБ $p_{1}>0.1 \mathrm{MPa}$. Поэтому приходом газа от сгорания порохового заряда можно пренебречь.

Графики изменения давления в МБ $(a)$ и внешний вид ТХЛ-элементов после испытаний $(b)$ приведены на рис. 2 (для элемента типоразмера D фирмы EVE ENERGY) и на рис. 3 (для элемента типоразмера DD фирмы EXIUM).
В таблице приведены экспериментальные данные по энергии взрыва и горения ТХЛ-элементов типоразмеров D и DD ряда производителей, полученные с использованием предлагаемой методики.

Экспериментальные данные по взрыво- и пожароопасности ТХЛ-элементов различных производителей, представленные в таблице, показывают, что тепловой эффект взрыва и горения элемента питания зависит не только от его энергоемкости, но и от конструктивного исполнения и используемых материалов при изготовлении элемента.

Таким образом, предлагаемая методика оценки взрыво- и пожароопасности ТХЛ-элементов позволяет спрогнозировать риски нештатного (аварийного) нарушения работы и негативное воздействие на аппаратуру и обслуживающий персонал и может применяться при испытании на внутреннее короткое замыкание любого первичного или вторичного химического источника тока.

\section{Финансирование работы}

Результаты исследования получены в рамках выполнения государственного задания Министерства образования и науки РФ (проект № 9.9036.2017/8.9).

\section{Конфликт интересов}

Авторы заявляют, что у них нет конфликта интересов. 


\section{Список литературы}

[1] Нижниковский Е.A. Современные электрохимические источники тока. М.: Радиотехника, 2015. 296 с.

[2] Белов О.И., Болдырев М.А., Воронцов П.С., Нижниковский Е.A. // Лесной вестник. 2012. № 2. С. 103-106.

[3] Нижниковский E.A. // Электрохимическая энергетика. 2001. T. 1. № 3. C. 39-44.

[4] ГОСТ Р МЭК 60086-4-2009. Батареи первичные. Ч. 4. Безопасность литиевых батарей. М.: Стандартинформ, 2011. $27 \mathrm{c}$.

[5] Похил П.Ф., Мальцев В.М., Зайцев В.М. Методы исследования процессов горения и детонации. М.: Наука, 1969. 301 с.

[6] Архипов В.А., Басалаев С.А., Коноваленко А.И., Кузнецов В.T., Бездворных Т.А., Войков Г.Г. Способ оценки взрыво- и пожароопасности химических источников тока. Заявка № 2018131617 на патент РФ. МПК F42B 35/00, Н01М 10/00. Заявл. 03.09.2018.

[7] Базаров И.П. Термодинамика. М.: Высш. шк., 1991. 376 с.

[8] Карауш С.A. Оценка параметров промышленных взрывов. Томск: Изд-во ТГАСУ, 2014. 96 с. 